\title{
El tratamiento de la enfermedad arterial femoropoplítea con balón liberador de paclitaxel tiene menor tasa de re-estenosis vascular que con balón convencional
}

Treatment with paclitaxel-coated balloon for femoropopliteal artery disease leads to a lower vascular stenosis rate compared to conventional balloons

\section{Objetivos}

Comparar la eficacia y la seguridad de los balones liberadores de paclitaxel en comparación a los balones convencionales en el tratamiento de la enfermedad arterial femoropoplitea sintomática.

\section{Diseño, lugar y pacientes}

Ensayo clínico controlado aleatorizado, simple ciego, multicéntrico. Fue realizado en 54 sitios en Estados Unidos, Austria, Alemania y Bélgica. Se reclutaron 476 pacientes $(63 \%$ hombres) mayores de 18 años con enfermedad arterial femoropoplítea sintomática (estadios de Rutherford 2 a 4), con estenosis mayor de $70 \%$ por angiografía, en lesiones no mayores de $15 \mathrm{~cm}$ de longitud.

\section{Intervención}

Se aleatorizaron a los pacientes en una razón de 2:1 a recibir tratamiento percutáneo con balones liberadores de paclitaxel $(n=316)$ o balones convencionales $(n=160)$. Sólo el médico operador no fue ciego al tratamiento ya que ambos balones lucían diferente.

\section{Medición de los resultados principales}

Se dispuso de un punto final primario de eficacia que correspondía a la tasa de permeabilidad del vaso tratado a los 12 meses. El punto final primario de seguridad consistió en un punto combinado de ausencia a 12 meses de amputación del miem-
Rosenfield K. y col NEJM 2015; 373:145-153. bro, revascularización y muerte relacionada al tratamiento del miembro afectado. El análisis se realizó por intención de tratar modificado. El seguimiento fue a 12 meses, con visitas al mes y a los seis meses.

\section{Resultados principales}

A 12 meses la proporción de pacientes con arteria permeable (ausencia de re-estenosis evaluada por ecografía) fue mayor en el grupo tratado con balones liberadores de droga en comparación con el tratamiento convencional $(65,2 \%$ vs $52,6 \%$, $p=0,02)$. Con respecto al punto final de seguridad, la proporción de pacientes libres del punto combinado de muerte, amputación y revascularización del miembro angioplastiado al año de seguimiento fue mayor en el grupo tratado con balones liberadores de paclitaxel $(83,9 \%$ vs $79,0 \%, p=0,005$, cumpliendo criterios de no inferioridad).

\section{Conclusión}

En pacientes con enfermedad arterial femoropoplitea sintomática, la angioplastia transluminal percutánea con balones liberadores de paclitaxel obtuvo una tasa de permeabilidad primaria a 12 meses mayor a la lograda con balones convencionales. EI tratamiento con balón liberador de droga cumplió criterios de no inferioridad respecto al tratamiento con balón convencional en cuanto al punto final de seguridad.

Fuente de financiamiento: Lutonix-Bard

\section{Comentario}

Si bien la angioplastia transluminal periférica con stents es una estrategia terapéutica efectiva que disminuye la tasa de re-estenosis y de retracción elástica (recoil) en el mediano plazo ${ }^{1}$, el tratamiento con balón continúa siendo una opción segura. Rosenfield y col. nos presentan un ensayo clínico aleatorizado en el que el tratamiento percutáneo de la enfermedad arterial femoropoplitea con balones liberadores de paclitaxel demostró mayor permeabilidad al año que los balones convencionales. Sin embargo, esta ventaja no se tradujo en beneficios clínicos para los pacientes: al año el índice tobillo-brazo, el estadio de Rutherford alcanzado y el cuestionario de calidad de vida no mostraron diferencias significativas, si bien el estudio no tenía el poder para evaluar diferencias en estos desenlaces clínicos. Al analizar el punto final combinado de seguridad, la ventaja del tratamiento con balones liberadores de droga se debió fundamentalmente a la menor necesidad de reintervención del miembro tratado, no hallándose diferencias significativas en puntos clínicos fuertes como la muerte o la amputación del miembro tratado.

\section{Conclusiones del comentador}

A pesar de los datos alentadores obtenidos en este ensayo, todavía se necesitan trabajos con seguimiento más prolongado y con el poder necesario no solo para demostrar la superioridad de un tratamiento sobre el otro desde un punto de vista imagenológico (permeabilidad evaluada por ecografía/angiografía), sino también para evaluar el potencial beneficio clínico.

Fernando Cohen [ Servicio de Hemodinamia y Cardiología Intervencionista del Hospital Italiano de Buenos Aires . fernando.cohen @ hospitalitaliano.org.ar]

Cohen F. El tratamiento de la enfermedad arterial femoropoplítea con balón liberador de paclitaxel tiene menor tasa de re-estenosis vascular que con balón convencional. Evid Act Pract Ambul. 2017;20(2):36. Comentado de: Rosenfield K y col. Trial of a Paclitaxel-Coated Balloon for Femoropopliteal Artery Disease. N Engl J Med 2015;373:145-53. DOI: 10.1056/NEJMoa1406235. PMID: 26106946.

\section{Referencias bibliográficas}

1. Schillinger M y col. Balloon Angioplasty versus Implantation of Nitinol Stents in the Superficial Femoral Artery. New England Journal of Medicine. 2006;354(18):1879-1888. 